\title{
SEEING MUSIC, MUSIC TO SEE-Interdisciplinary Relations between Musical and Visual Art Education in Italian Pre-School and Primary School ${ }^{+}$
}

\begin{abstract}
Antonella Coppi
Faculty of Education, Free University Bozen-Bolzano, 39100 Bolzano BZ, Italy; antonella.coppi@unibz.it, Tel.: +39-347-5324736

+ Presented at the International and Interdisciplinary Conference IMMAGINI? Image and Imagination between Representation, Communication, Education and Psychology, Brixen, Italy, 27-28 November 2017.

Published: 5 December 2017

Abstract: The practice of music represents an irreplaceable experience of the human being. Gratifying in many aspects, it carries out a diversified web of experiences: sensorial, perceptive, cognitive, dynamic, social, cultural. In this, each individual comes to the progressive realization of music as an integrated and integrating experience, which is the deep meaning of culture and the ability to establish relationships. The education to artistic languages encountered in pre-school and primary school, even when it is of less relevance in the curriculum, should represent a crucial base to the learning pathway, while promoting interdisciplinarity and warranting a new plurifocal access to knowledge and to individual growth, which is capable of reinforcing also other knowledge necessary in questioning and comprehending the essential, structural, communicative, creative, imaginative and psychological aspects linked to the use of every genre of art.
\end{abstract}

Keywords: music; education; arts; interdisciplinarity; school

\section{Introduction}

In his work Trattato della pittura (1550 ca) (Leonardo's writings on painting--among the most remarkable from any era-were never edited by Leonardo himself into a single coherent book. In this anthology the authors have edited material not only from his so-called Trattato della pittura (Treatise on Painting) but also from his surviving manuscripts and from other primary sources, some of which were here translated for the first time. The resulting volume is an invaluable reference work for art historians as well as for anyone interested in the mind and methods of one of the world's greatest creative geniuses), Leonardo contrasts music and painting and decidedly declares to be in favour of the latter, affirming:

“[...] painting excels and lords over music because it does not die as soon as it is born, as occurs with music, the less fortunate; on the contrary, it continues to exist and reveals itself to be what it is, a single surface" ("Painting excels and rules over music since its death is not immediate to its creation, as the unfortunate music is, or rather, it remains in life, displaying to you in real life what in fact is only a surface").

Therefore with these words, Leonardo indicates that painting is of a superior position compared to music, because painting, as fixed on the canvas, never dies away after its creation, while music on the other side is closely linked to the moment and cannot be fixed in time.

He exalts the art of painting because,

"[...] quella cosa é più nobile che ha più eternità" e dunque: la musica che si va consumando mentre ch'ella nasce, é men degna della pittura che con vetri si fa eternal" (More noble is 
the thing that has more eternity therefore: music, which consumes itself in the moment of its birth, is less deserving compared to painting which becomes eternity in glass (Personal translation editing)).

Evidently, in Leonardo's times, the images produced by him either through painting or drawing, were static images destined to last unchanged in time. Nowadays the cinema and television have accustomed us to continuously moving images which are far from being eternal". Nowadays the imagery culture has become a characterizing and primary element in the life of contemporary society and also the musical experience has been following this approach, when it comes in contact with the production of light music promoted through a video or is preparing to design scenographic imagery for an opera landscape. The same can be said for the choreographic art, not to mention "programme music (Program music or programme music is a type of art music that attempts to musically render an extra-musical narrative. The narrative itself might be offered to the audience in the form of program notes, inviting imaginative correlations with the music)" which historically can be considered "Music to see". All the musical production whose titles unequivocally evoke visual or literal-visual associations can be related to these genres, from various perspectives and on various levels [1]. "Pure music" (Absolute music, pure music is music for its own sake, concerned only with structure, melody, harmony, and rhythm), which is all chamber music production whose only reference is just the musical form of it, seems exempt from these "contaminations", at the same time however is still stimulates imaginative associations linked to larger cultural and perceptive contexts which are also connected to the context of composition and musical performance. From the educational point of view, the basic schooling education and particularly musical education rarely seems to be able to approach these associations and phenomenon: sometimes they take on and empirical approach, not very far from the stimulation towards graphic representation that children from pre-school and primary school are incited to, which is to represent a narrative outline more or less related to the composers' explicit programmatic declarations during the listening phase, which would be more effective from the educational point of view, is approached as an activity to solely experience. On the other hand, the undeniable specificity of a part of musical codes constitutes a reason for many teachers to neglect-depending on personal competencies-and underplay the detailed study relative to the decoding and encoding of musical languages or, on the other extreme, to resolve the whole visual and musical approach in terms of pure and mere tecnique and grammar, without paying attention to the psychological needs of artistic learning and the profound sense of culture as the ability to establish relationships.

The whole musical experience of humanity has been a continuous creative activity of elaboration of heterogeneous connections and contaminations. Too often the existence of this process, which is slow and everything but linear, is forgotten. In musical institutions as well (from primary education to academies) the disciplines would became divided worlds, which were absolute and uncommunicating, while in the real musical life the connection with everything else is alive, in life, in knowledge and in arts. In the same way one could refer to the whole history of musical theatre, for instance (Lyric Opera and other), without the decisive contribution of literature, of scenography, of architecture, of painting, of mechanical technique, of managerial organization, of the press, of the public, etc. Also in the case of "average" instrumental concerts, music becomes theatre: in the implicit gestures in playing the instrument, in the positioning of the players and the public (and in their interactions), in the relationship with the location of the concert, etc. In some way it could be said that the musical event is always a scenic and theatrical action, that is the most complex artistic invention of humankind. Real music therefore, is never isolated, not even when a single person, alone, is singing, playing music or dancing because even in these places and instants, physical synapsis, which are emotional and cultural, are activated, therefore it is to be considered a real universal experience.

\section{Musical, Visual and Space-Time Perceptions in Children's Artistic Learning}

Psychological studies that deal with languages and relationships with the perceptive world, have long proved that visual perception is determined by the synthesis our brain performs for each image, combining many time points [2]. The set of these points builds the sensation of a visual unit 
that the child encodes as a recognizable visible form [3]. The founding element of this decoding process is the mixture of many factors, first of all movement, then memory and finally the surprise element.

To illustrate with an example, if we see an animal moving between the leaves of a bush, not only the contours of the object will provide useful information, but also the set of points that form the trajectory of the moving element, its velocity, the characteristics of its kinetic behaviour: through these components we can also understand its intentions.

This approach to the visual form stimulates the synthetic ability of each individual, an extremely complex operation that our brain develops in a tenth of a second, and acts as a sorting tool for those parts of the disturbing visual landscape that do not correspond to the mental image that reached us [3].

To this process, the child just as the adult, combines a mental operation in order to evaluate what they observe in function of a memory of how similar it has been compared to the past experience or represents a novelty, a surprise: as Corrado Ricci [4] depicts, if the subject of any age is exposed to the vision of a certain object and does not recognize it as known, the question arises about what it is, searching for associations with what has already been similarly experienced before.

The mental association of the elements we know and of those we ignore, therefore, help us to classify what we have seen, either as known or as unknown.

As far as music is concerned in the relation to the perceptual world, to make auditory recognition happen, the presence of some presuppositions that refer to the historical and crystallized codification of the signs in the auditory-cultural memory are necessary. If no codes subsist, from education, from ethnic origin, from culture, in music no one can understand the auditory-musical event and classify it as known, since he cannot identify anything that distinguishes it [5].

The first recognizable sounds certainly refer to those that belong to nature and to the early circumstances of our existence: the study of pre-natal experience helps us in understanding how the fetus can recognize the voice of its mother since the early days of life, because this sound is part of his experience that will certainly have an effect on the subsequent behavior of the newborn.

Therefore the action of "initial seeing/listening" on things/sounds intended as "figures" transforms itself to "presuming to see/listen", which consents to the perceived "thing" to take on a meaning [6].

Forms, colors, scents, sensations accepted in this provoking relationship would have been the analogical inspiration to compose pictures, music, poems, words and representations, means or ways to the understanding of the environment in itself. In this condition, the subject perceives what is hidden, the reality concealed beyond appearances, towards the essence of things. These responsive reactions are expressed in the form of movements, gestures, rhythmic movements surrounded by sounds, reworked in dreamlike images. Such gestures could be interpreted as the "multimedia" essence of the learner: they are contained within the body space and in the time that exists between one gesture and the other. Therefore space-time perception is related to motor and rhythmic activities and therefore to corporeity. Musical expression becomes such a communicative act that it can be considered as the emergence of a psychic movement within a corporeal movement.

To express is therefore to reveal oneself to others through every communicative figure-language related to one's personality and to the identity that is put in relation to others. The body is the hub around which revolve the various languages that originate from it and through which they manifest: nowadays children which are exposed to a complex world of signs, codes, flavors and models, must be guided in the construction of their own competencies in contact with the solicitations of an environment which is deeply marked by the "multimedia" character of forms of communication and information. The lifestyles, the organization of times, spaces, and social behaviors create a kind of "multimedia alphabet" that confers the child's communicative space and enters in his daily spaces through forms of communication (written, advertising, musical language), filling them with content (information, knowledge, entertainment). 


\section{Music and Visual Arts: Sinesthetic Relationship and Imagination as a Learning Tool}

Scientific research catalogs, orders, classifies and because of this it has to keep its distances from the observed object, trying not to be confuse itself with it, in order to eliminate anything that can numb the very action of knowing. In this perspective, the learning subject places itself in a position of supremacy on reality, though losing the spontaneity of an immediate, dreamy, imaginative, more free approach to the associations that shape, structure and colors revoke in them by analogy. In the relationship with arts, the subject that learns puts the senses into action, which are non-passive receptors in the face of the show that is outside world, which captures in various instances of life the colors, smells, flavors, forms that, by analogy, relate to objects and situations of the historical past of the individual himself [7], thereby contributing to the learning and attribution of meaning.

The core of this approach is the innate and involuntary ability of each individual to associate images of all senses-with connected languages - while stimulating only one of them. This goes under the name of synesthesia. Synesthesia is generally known as the rhetorical figure with which two terms that belong to different sensory spheres are put near each other: a bright scent, a sharp taste, a fresh word. The same etymology of the word suggests it: coming from the Greek sýn "with, together" and aisthánomai "perceive, understand"; therefore meaning "I perceive together".

Synesthesia, however, is also a sensory perceptual phenomenon (real and widely studied since the last decades of the twentieth century), because of which, in some individuals, a stimulus in a single sensory mode (for instance, hearing) unintentionally causes a feeling in another mode (such as in sight). It is that kind of unconscious (or conscious) ability that allows children to take advantage of their sensorial experience to learn, which is expressed primarily through non-verbal languages, in a real contact-dance with the world; a dialogue that begins in the prenatal period with the maternal womb and continues, widening to all other beings, well beyond the moment in which the acquisition of verbal language occurs. Children, in their ability to easily cross the limitations set by the intellect which delimit the areas of knowledge, are not interested in fragmenting knowledge and skills, but rather, because they can intensely feel the unity and intimate connection, can even show to adults the way to revert to being "polyglots" of life, capable of understanding the many lexis of the arts.

In this direction, the learning of artistic languages finds in synesthetic translation a very effective means of vehiculation of knowledge, being able to swap easily from one another, manipulating a material and modifying another [8] (pp. 163-172): meeting various materials, moving, drawing, coloring, manipulating consitute the opportunity to meet, live and experiment with the auditory component of such materials, in the same way it is possible to transpose into music all the actions and/or productions that derive from it.

An intense "graphic track" already expresses intense sound in its motion (can be seen by percussing a musical instrument in the same way); just as the continuity of the line is the visible trace of a prolonged sound that moves in high or low space (high or low) according to its own undertones (gradations and timbres) and tonality: therefore we can also translate the other parameters of translation of expression as well, while contemplating its meanings.

To contemplate means also to learn how to rhythmically sync with the rhythm of another individual and/or object. It is this "tendency" that teachers should seek to enhance in pupils, while enriching their observation ability, to gain an artistic understanding of the world.

In music, it is sound which has the particular ability of synesthetic solicitation. It is in its own physical nature: it is aimed at the ear, but at the same time-in addition to providing an irresistible source for visual imagination-sets in motion tactics and proprioceptions [9]. As a matter of fact, as Johannella Tafuri writes: "When we talk of hearing perception processes, one should not forget that not only the ear participates but also the touch (body vibrations), the sight (to see who is playing) and the kinesthetic sense or muscular sense (body positions, feeling of tension or relaxation, etc.)" [10] (p. 15). Evidence of this reality is part of the daily experience of every child who if exposed to listening to a high volume of music, with the high level of vibration for instance, he often becomes conscious of the physical and corporal pervasiveness of auditory perception.

These direct sensory stresses are accompanied by perceptions of reverberation, induced and constituted by the representative hints that sound provides with its qualities. As Salvatore Sciarrino 
writes, "a loud sound pushes out to touch, it threatens us it runs us over it overwhelms us, a quiet sound goes away and our impulses quieten down". The same is true for other characteristics of sound such as timbres, heights, durations, capable of evoking other spaces, whether they are visual, tactile, or proprioceptive [11] (pp. 78-86). It is precisely this set of perceptive factors, direct and induced, that constitute for generations of artists, and even more for teachers of musical education, a reason to practice the imaginary as well as the visual, finally pushing them to evade their art in favor of referring to another.

\section{The Musical and Visual Arts in the Hundred Languages of Children}

"Playful didactics", cooperative learning, "learning to learn". These are the key words summarizing the laboratory approach of the didactic experience in the pre-schools and primary schools that adhere to the Reggio Emilia Approach. This pedagogical and didactic model, born in Reggio Emilia in the 90s from an idea of the pedagogue Loris Malaguzzi, is based on the image of a child with innate development potential and a rights holder, who learns and grows through relationships with other people (teachers, parents, family, community) through the subsidy of the "Hundred Languages", within which arts occupy a privileged position. This model therefore constitutes a very effective example of how musical education and visual-artistic education can be in an interdisciplinary relationship in Italian Pre-school and Primary school.

As a matter of fact, in Reggio Approach the arts have great importance in the children's pedagogical experience. Arts are learned in the spaces of the atelier with the help of the figure of the atelierist (Atelierista, a "teacher" with skills of artistic nature) such as music, dance, visual arts, theatre. This orientation uses expressive languages as part of the process of acquiring knowledge: the Atelier thus becomes the site of research, invention, empathy, which is expressed through the "Hundred Languages" and that, expanding beyond the age of Childhood, also includes adult age, until old age.

Because of the use of expression languages that are more combined and integrated, each of them grows and helps the development of the other " 99 "!

As the pedagogue Loris Malaguzzi (Loris Malaguzzi (Correggio, 1920-Reggio Emilia, 1994)pedagogue and pedagogist -is best known for his instrumental role in the creation and development of the Reggio Emilia approach - the child-centered early educational philosophy that hinges on the belief that children are powerful and capable individuals, with the ability and desire to construct their own knowledge. Throughout his education, Malaguzzi became heavily influenced by several different educational theorists: John Dewey, Erik Erikson, Jean Piaget, Lev Vygotsky, and Barbara Biber. As a constructivist, Malaguzzi's influences led him to the belief that each person constructs their own knowledge through their own life experiences, and that children are no different. Each of his influences left a different impact, as each of their educational philosophies had unique approaches. http://www.thecompassschool.com/blog/who-is-loris-malaguzzi/) stated:

"The speech strengthens and expands through the gains coming from other languages that are all built through experience (therefore we talk about the interfering nature of the languages). However here it is essential to note that even languages that are not spoken have many words, feelings and thoughts, many desires and means for knowing, communicating and expressing oneself. They are also ways of being, acting, image generators and complex lexics, metaphors and symbols; organizers of practical and formal logic, promoting personal and creative styles" [12] (pp. 49-97).

The pedagogical model presents itself as a global educational approach that has inspired schools around the world, and its main strength is a multifocal opening of the child's individual knowledge and growth: every skill emerges during activities and is experienced through the contemporary active use of hands, thought, emotions, perceptions, enhancing the expressiveness and creativity of the subject as such and also as a member of the society.

In this context, through taking advantage of the common elements of art and music, the visual arts atelier can find an extension in the music atelier [13] (pp. 34-35) and vice versa, to contribute to 
the building of a combined learning of materials, meanings and structures [14] (pp. 82-90). Ideed, the understanding of music can be influenced by the use of visual images and these images can represent sounds and musical gestures [15] (pp. 216-222).

As Wendell Hanna (Wendell Hanna, is Professor of Music Education in the School of Music at San Francisco State University) explains effectively:

"The most striking commonality between music and art is that both are non-verbal languages. But in addition, there are elements of art and music, which share striking commonalities. The standard visual art elements are line, color, texture, value, space, shape and form. These elements in the visual arts atelier correlate with elements in music in interesting ways" [16] (pp. 287-294).

Thus, according to the American pedagogist, professor at the University of San Francisco, there are many similarities between music and visual art: in addition to the ones described above, what must be added is the "color" similar to the music timbre that children can perceive since newborns [17], which in art is considered a combination of tonality, color and duration. In music, the timbre is determined by a set of frequencies with an attack, decay, and release, and although they seem like a difficult concept, are easily recognizable by children if associated with body movement. The concept of "Texture" in art is similar to that in music. In art, texture is something that can be touched and felt: the texture may be scratchy, tough or soft, rough, smooth. In music, the plot is made up of different sounds combined with each other, which make up its texture. For example, in listening to voices and instruments that are on time and move in the same direction, the child perceives its smooth consistency, which becomes rough when the voices or instruments change direction and movement. "Space" is another common element between visual arts and music: it has a role in art which is comparable to what music has in the rhythm. "Space" in art refers to distances or internal or external areas, referring to what is illustrated in the work, and is also created through the use of different materials such as natural ones, metals, stones on all of which "space" is created. In music, material is made up of "time", which creates various rhythms when mixed with space and silence.

Finally, another fundamental element is shape which distinguishes the visual arts from the musical arts. As Wendell Hanna points out:

"Form in art has three dimensions: length, width, and depth. Similarly, harmony in music is created when two or more pitches are sounded simultaneously and is also multidimensional. Separate pitches in music come together through harmony in distinct new ways, and it is often difficult to hear the separate pitches when they are played together as complex "sound-forms" known as musical chords" [16] (pp. 287-294).

The above described offers to the teacher a formidable pedagogical tool for the development of the arts' learning, which uses the perceptual experiences of children, activated through what they already know, in a sinesthetic approach and of shared understanding. In the Music and Visual Arts Atelier, children explore and experience the related languages, learning how to manipulate them with the help of atelierists, often professional artists. The children develop individual and group expression in this process. The child's imagination and his world of emotions constitute key elements for the growth and development of personality: the emotional experience and the abstractions that it evokes in every individual take on a significant value that, as Nicky James suggests in a stimulant essay dedicated to "Emotional labour" (Emotional labour (or Emotion at work): the labour involved in dealing with other peoples' feelings, a core component of which is the regulation of emotions. http://onlinelibrary.wiley.com/doi/10.1111/j.1467-954X.1989.tb00019.x/abstract) [18] (p. 15), it also constitutes a "social work", as social expression of emotion [18] (p. 19). In the Pre-school and Primary school, the Reggio Approach model can constitute a formidable tool for exploring the interplay of relationships between visual arts and music, opening up a learning dialogue that will benefit both, while enhancing the learning of many other transversal skills that will help the child become an adult. 


\section{Conclusions}

This work sought to provide a multi-faceted look at the educational relationship underlying the language of the arts, touching on some preparatory informations in the fields concerned: the main directions of some international pedagogical experiences are the background in which to incorporate the interdisciplinary artistic experience in pre-school and primary school, aimed at stimulating and tackling in a pedagogically, didactically and psychologically correct way, the complex relationships between musical education and imagery education. The pedagogic orientation of the Reggio Approach continues to be one of the most suited to developing, manipulating and experimenting the education to the visual arts in all schools around the world to which the main elements of musical education can be integrated, forming a very effective mix of sounds, colors, images and perceptions that contribute to the development of the child and of his/her extraordinary potentials in learning and change. The numerous affective resources that each individual in the process of learning possesses, the relational ones, sensorial, intellectual ones explicit themselves in an continuous exchange through the social and cultural context. Every child is a rightholder and as a priority possesses that of being respected and valorized in his/her own identity, uniqueness, difference and also in their own development times and artistic growth. Every child whether as an individual or in relation to a group, brings sensitivity and synesthetic capabilities that are applied to the understanding of the environment to build educational experiences in which he is able to find sense and meaning. The similarities betweeen the visual arts and music can constitute an important pedagogical tool in contributing to the development of the child's personality, since music and visual arts share the "visions", "translations" and relaltionships with other disciplinary areas, which enrich and become an important path to comprehend and appreciate of languages and their structures.

\section{References}

1. Montiglio, I. Dentro e fuori la musica. Itinerari didattici nella prospettiva della musica aperta al mondo delle arti motorio-coreutiche, visive, figurative, ludico-espressive. In Metodi e Strumenti per L'apprendimento e L'Insegnamento della Musica; Comploi, F., Coppi, A., Eds. Edises: Napoli, Italy, 2014; ISBN 8865845139.

2. Arnheim, R. Arte e Percezione Visiva; Feltrinelli: Milano, Italia, 2005; ISBN 978-8807100239.

3. Maffei, L.; Fiorentini, A. Arte e Cervello. Zanichelli: Bologna, Italy, 2008; ISBN 978-8808068156.

4. Ricci, C. L'arte dei Bambini; Armando Editore: Roma, Italy, 2007; ISBN 9788860813169.

5. Schön, D.; Akiva-Kabiri, L.; Vecchi, T. Psicologia della Musica; Carrocci Editore: Roma, Italia, 2012; ISBN 9788843040605.

6. Sloboda, J.A. La Mente Musicale. Psicologia Cognitivista della Musica; Il Mulino: Bologna, Italia, 2002; ISBN 978-8815088253.

7. Ehrenzweig A., La Psicoanalisi della percezione nella musica e nelle arti figurative; Editore Astrolabio: Roma, Italia, 1977; ISBN 9788834000359.

8. Cunliffe, L. Synaesthesia - Arts Education as Cross-Modal Relationships Rooted in Cognitive Repertoires. Int. J. Art Des. Educ. 1994, 13, 163-172.

9. Riccò, D. Sinestesie della musica. Interscambi fra immaginazione sonora e rappresentazione visiva. Hortus Music. 2003, 4, 14.

10. Tafuri, J. Psicologia Genetica Della Musica; Bulzoni: Roma, Italia, 1991; p. 15.

11. Riccò, D. Stereotipìe dell'ascolto. IL Verri 1997, 4-5, 78-86.

12. Malaguzzi, L. L'educazione dei cento linguaggi dei bambini. In The One Hundred Languages of Children: The Reggio Emilia Approach-Advanced Reflections; Edwards, C.P., Gandani, L., Forman, G., Eds.; Ablex Publishing: Westport, Ireland, 1998; pp. 49-97, ISBN 978-1567503104.

13. Stephens, S. Music you can see. School Arts 2012, 112, 34-35.

14. Nelson, J.; Zobairi, N. Multiple literacies: The whole mind at work. Int. J. Early Child. 1999, 31, 82-90, doi:10.1007/BF03166900.

15. Logue, M.; Robie, M.; Brown, M.; Waite, K. Read my dance: Promoting early writing through dance. Child. Educ. 2009, 85, 216-222, doi:10.1080/02568540903439375.

16. Hanna, W. A Reggio-Inspired Music Atelier: Opening the Door between Visual Arts and Music. Early Child. Educ. J. 2014, 42, 287-294, ISSN 10.1007/s10643-013-0610-9. 
17. Trehub, S. E. Musical predispositions in infancy. Ann. N. Y. Acad. Sci. 2006, 930, 1-16, doi:10.1016/j.evolhumbehav.2016.12.005.

18. James, N. Emotional labour: skill and work in the social regulation of feelings. Sociol. Rev. 1989, 1, 15-42, 10.1111/j.1467-954X.1989.tb00019.x.

(C) 2017 by the authors. Licensee MDPI, Basel, Switzerland. This article is an open access article distributed under the terms and conditions of the Creative Commons Attribution (CC BY) license (http://creativecommons.org/licenses/by/4.0/). 